\title{
How to turn a (not-yet-)possessed DP into a predicate nominal in Cochabamba Quechua Neil Myler ${ }^{*}$
}

LSA Annual Meeting, Minneapolis, January 2-5, 2014

1. Introduction. In this paper, I focus on a relatively unfamiliar subtype of BE-based possession construction discussed by Stassen (2009:157-185), which he dubs predicativization. One aim will be to show, in the spirit of Boneh \& Sichel (2010) and Levinson (2011), that this is truly a phenomenon distinct from other subtypes of $\mathrm{BE}$ construction, and that it cannot be related to more familiar subtypes of possession sentence via movement. A second aim will be to provide an analysis of the construction which uses independently-needed mechanisms from recent theories of argument structure (Kratzer 1996; Marantz 2013; Wood 2012, i.a.) and which will ultimately feed into a parametric theory of how possession sentences are built and interpreted more generally (such a theory is developed at length in Myler 2014).

2. Possessees made into predicate nominals/adjectives? Stassen (2009:157-185) points out what looks like a set of possession constructions in which the possessee appears as the predicate of a copular sentence. In these constructions, the possessee is often marked with some kind of derivational morpheme, which can be a nominalizer or an adjectivalizer. Since the role of the derivational morpheme seems to be to convert the possessee into a predicate, Stassen refers to this phenomenon as predicativization. Examples from Andoke and English are provided in (1) and (2). Andoke apparently employs a nominalizing suffix in these constructions. English employs the suffix -ed, which in this case appears to be an adjectivalizer (since-ed-marked phrases pass the seem test).

$$
\begin{aligned}
& \text { Andoke (Stassen 2009:162) } \\
& \text { Puke-koá b-aya. } \\
& \text { Canoe-NMLZ FOC-3SG.M.SUBJ } \\
& \text { 'He has a canoe.' }
\end{aligned}
$$
a. John is blue-eyed.
b. John seems blue-eyed (in this light).

If Stassen is correct, then Universal Grammar permits a class of derivational morphemes which can convert a possessee into a predicate. Stassen's discussion still leaves room for some skepticism, however. Firstly, many of the languages used by Stassen to motivate the existence of predicativization are understudied, which makes it possible that closer inspection will reveal ways to assimilate cases like (1) to more familiar subtypes of possession construction. While the descriptive issues in the case of English (2) are nowhere near as extreme, for English -ed there is a plausible counteranalysis (advanced in different forms by Pesetsky 1995:311 and Tsujioka

\footnotetext{
${ }^{*}$ Unless otherwise noted, all of the Cochabamba Quechua data reported here were gathered during fieldwork in Cochabamba, Bolivia. My profound thanks go to María Cardoza, Gladys Camacho Rios, and Cristina Puente Arista for sharing their language with me. The fieldwork was supported by NSF Doctoral Dissertation Research Improvement Grant BCS-1324839. This extended abstract summarizes a talk which was delivered when the author was a graduate student at New York University, and a more detailed version of the analysis appears in my doctoral dissertation (Myler 2014:318-346). I am very grateful to audiences at MIT, NYU, and the LSA Annual Meeting for their feedback, and particularly to Gillian Gallagher, Stephanie Harves, Richard Kayne, Pieter Muysken, Anna Szabolcsi, and my advisor Alec Marantz. Remaining errors and infelicities are mine alone. Author: Neil Myler, Boston University (myler@bu.edu).
} 
2002:165) in terms of a silent HAVE verb which has been passivized. ${ }^{1}$ The rest of this paper is devoted to giving an existence proof that Stassen is in fact correct, and to providing a generative account of predicativization which yields interesting predictions concerning parametric variation.

3. The Quechua suffix -yoq. The existence proof for the reality of predicativization comes from the morpheme -yoq, which is found in all languages of the Quechua family (Cole 1982:94; Pieter Muysken pers. comm.). The morpheme is illustrated in (3), which is a predicative possession construction (this and other examples in this paper come from Cochabamba Quechua, a Bolivian variety).

(3) Noqa [ashkha puka auto-s]-ni ${ }^{2}$-yoq ka-ni.

I many red car-PL-EUPH-YOQ be-1SG.SUBJ

'I have a lot of red cars.'

My claims about the $-y o q$ construction are as follows. ${ }^{3}$

(4) Main Claims about the -yoq Construction

a. Morphosyntax I: The $-y o q$-marked phrase is nominal in nature, hence (3) is a copular construction with a nominal predicate.

b. Morphosyntax II: $-y o q$ itself is a phrasal derivational little-n, i.e., it merges with a DP and starts a new nominal extended projection.

c. Semantics: - yoq takes as its first argument a relation- that is, a possessed DP which is "missing" its possessor- and outputs something of the type of a common noun.

Given the claims in (4), a simple possession sentence employing -yoq will have the structure in (5) (abstracting away from the base position of the subject, as well as certain other irrelevant issues).

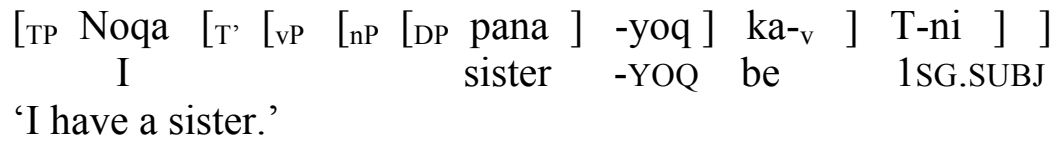

'I have a sister.'

A number of morphosyntactic facts support the claims in (4) and the structural representation in (5). First, the external distribution of -yoq-marked phrases is compatible with their being nominal, but incompatible with their being adpositional. ${ }^{4}$ Adpositional phrases contrast with noun phrases in not being able to stand alone in subject or object position. With respect to this diagnostic, -yoq-marked phrases clearly pattern with nominals (for reasons of space, exemplification is given for the case of subject position only).

\footnotetext{
${ }^{1}$ See, however, Nevins and Myler (2014) for criticism of these approaches to English -ed.

${ }^{2}$ The suffix $-n i$ is glossed EUPH for 'euphonic suffix', because it appears in order to break up illegal syllable structures created by the concatenation of suffixes on nouns.

${ }^{3}$ I note that claims (4a) and (4b) are in fact (Distributed Morphology/Minimalist Program translations of) the standard analysis of the $-y o q$ construction in the descriptive Quechua literature, including in work by linguisticallytrained native speakers of Quechua (for references, see http://tinyurl.com/p4p5szy). However, with the exception of Hoggarth (2004), this literature does not provide explicit argumentation in favor of these claims, and not even Hoggarth provides evidence against plausible alternatives.

${ }^{4}$ This means that it is not possible to claim that $-y o q$ is a postposition corresponding to with, and thereby assimilate the $-y o q$ construction to WITH possessives of the sort discussed for Icelandic by Levinson (2011). Note that there is also evidence that, for at least some speakers, $-y o q$ is definitely nominal and not adjectival- namely, some speakers disallow adjectives from standing alone in subject position (an observation which originates with Adelaar 1994).

For such speakers, examples like (7) confirm that -yoq-marked phrases are not adjectival.
} 
(6) Kay wawa-s-wan *(ka-q) reqsi-wa-n.

This child-PL-with be-REL know-1SG.OBJ-3SG.SUBJ

'This one who is with (i.e. in the company of) the children knows me.'

(7) Kay wawa-s-ni-yoq (ka-q) reqsi-wa-n.

This child-PL-EUPH-YOQ be-REL know-1SG.OBJ-3SG.SUBJ

'This one who has children knows me.'

Secondly, -yoq-marked phrases in argument positions can take their own plural morphology. If the possessee is itself plural, this results in plural morphology appearing both inside and outside of $-y o q$, as in (8). This is precisely what is expected if $-y o q$ attaches to a DP and starts a new nominal extended projection, as per $(4 b)$.

(8) Ashkha wasi-s-ni-yoq-kuna jamu-sha-n-ku.

Many house-PL-EUPH-YOQ-PL come-DUR-3SG.SUBJ-PL

'People who have many houses are coming/many people who have houses are coming.'

For further evidence and arguments, see http://tinyurl.com/p4p5szy.

A couple of potential alternatives to (4) suggest themselves, but neither stands up to scrutiny. Both take advantage of the fact that $-y o q$ ends in $/ \mathrm{q} /$, which also occurs as an agentive nominalizer and as a subject relative clause marker in the language. The question raised is therefore: could -yoq constructions involve a sort of synthetic compound along the lines of house-owner, or a relative clause along the lines of one who has a house? The answer to this question is 'no'. The -yoq-marked phrase cannot be a synthetic compound because Quechua synthetic compounds do not allow plural morphology on the non-head (just as is famously true of English: *rats-eater), but this is possible with -yoq, as shown by many of the examples above. Nor can the -yoq-marked phrase be a hidden relative clause, since relative clauses involve accusative case assignment to their direct object, something which is categorically disallowed in -yoq marked phrases. For exemplification and further arguments, see the above URL and Myler (2014). I conclude that $-y o q$ truly is a derivational little-n, and therefore that predicativization as defined by Stassen exists.

One question arising from this conclusion is how predicativization is achieved semantically. I propose that the denotation of -yoq (and other predicativizing morphemes crosslinguistically) is as follows.

$$
\lambda \mathrm{R}_{<\mathrm{e}<\mathrm{e}, \mathrm{t}>} . \lambda \mathrm{x}_{\mathrm{e}} \cdot \exists \mathrm{y}_{\mathrm{e}} \cdot \mathrm{R}(\mathrm{x})(\mathrm{y})
$$

This denotation takes a relation $\mathrm{R}$ as its first argument, existentially closes the second argument of that relation, and returns a predicate of individuals whose argument is identical to the first argument of R. In a predicativization structure, the relation which (9) takes as its first argument will be supplied by the possessee. Following Barker (1995), I take it that noun roots can either be inherently relational (like pana 'sister' in (5)), or they can be made relational by merging with Poss, a functional head in the extended projection of DP (this would be the analysis of an alienable possession case like (3)). Crucially, the derivation of a predicativization structure involves introducing a possession relation (via the inherent semantics of the root or via Poss), but not saturating that relation directly in the syntax, since no possessor DP is introduced internal to the possessed DP. It is in this sense that predicativization involves turning a (not-yet-)possessed DP into a predicate. 
4. Conclusion and implications for parametric variation. I have argued, supporting Stassen (2009:157-185), that there really are derivational morphemes that can take a relational(ized) noun (i.e., a possessee) and turn them into a predicate. Embedding a predicate derived in this manner under a copular verb is one way in which a language can build a possession sentence. I have suggested that such morphemes are derivational little-x's in the Distributed Morphology sense, and that they have a semantics that maps a relation to a predicate. This analysis gives rise to the following expectations about possible parameters of variation.

(10) Possible Parameters of Variation in Predicativizing Morphemes

a. The category of the derivational morpheme itself (e.g. $-y o q=n$, English $-e d=a$ )

b. The size of the DP substructure that it embeds.

This gives rise to an interesting prediction; namely, there should be a correlation between (10b) and the sorts of possession relation that these morphemes are compatible with in different languages. In particular, alienable possession should be possible only if the derivational morpheme embeds a DP substructure big enough to contain PossP. Otherwise, we expect a restriction to inalienable possession. Some sign that this prediction is correct comes from comparing -yoq with the English - ed construction (see also Nevins \& Myler 2014).

(11) a. *John is blue-carred.

b. John is blue-eyed.

c. *John is lovely big blue-eyed.

English $-e d$ cannot combine with fully phrasal possessees, and is instead restricted to combining with possessees of compound size (compare $11 \mathrm{~b} \& \mathrm{c}$ ). This, I now claim (following Nevins \& Myler 2014), is what restricts it to inalienable relations (compare $11 \mathrm{a} \& \mathrm{~b}$ ): -ed requires a relation semantically, and this relation has to come from the root itself given that -ed embeds a substructure too small to contain the Poss head. We have seen in (3), however, that $-y o q$ can embed larger DP substructures, and this is why it differs from -ed in being able to express both alienable and inalienable relations. Future work should test this predicted cross-linguistic correlation between the size of the embedded possessee DP and the types of possession relation that can be expressed.

\section{References}

Adelaar, Willem F. H. 1994. Review of A Grammar of Huallaga (Huánuco) Quechua, by David John Weber. International Journal of American Linguistics 60(1). 83-87.

Barker, Chris. 1995. Possessive Descriptions. Stanford University: CSLI Publications.

Boneh, Nora \& Ivy Sichel. 2010. Deconstructing Possession. Natural Language and Linguistic Theory 28. 1-40.

Cole, Peter. 1982. Imbabura Quechua. Amsterdam: North Holland Publishing Company.

Hoggarth, Leslie. 2004. Contributions to Cuzco Quechua Grammar. Bonn: Bonn Americanist Studies.

Kratzer, Angelika. 1996. Severing the external argument from its verb. In Rooryk, Johan \& Laurie Zaring (eds.), Phrase Structure and the Lexicon. Dordrecht: Kluwer.

Levinson, Lisa. 2011. Possessive WITH in Germanic: HAVE and the role of P. Syntax 14(4). 355-393.

Marantz, Alec. 2013. Verbal argument structure: events and participants. Lingua 152-168.

Myler, Neil. 2014. Building and Interpreting Possession Sentences. New York University Dissertation.

Nevins, Andrew \& Neil Myler. 2014. A Brown-Eyed Girl. Lingbuzz/002021

Pesetsky, David. 1995. Zero Syntax: Experiencers and Cascades. Cambridge, MA: MIT Press.

Stassen, Leon. 2009. Predicative Possession. Oxford: Oxford University Press.

Tsujioka, Takae. 2002. The Syntax of Possession in Japanese. New York: Routledge.

Wood, Jim. 2012. Icelandic Morphosyntax and Argument Structure. New York University Dissertation. 